\title{
The Implementation of Portfolio Assessment in Integrated English Course
}

\author{
Jizhen Huang $^{1}$ \\ ${ }^{1}$ School of Foreign Languages, Xuchang University, China \\ Correspondence: Jizhen Huang, School of Foreign Languages, Xuchang University, Xuchang city, Henan \\ Province, China, 461000. E-mail: hjizhen@126.com \\ The research is sponsored by Henan Provincal philosophy and social science foundation of China \\ "Experimental Study on the Implementation of Portfolio Assessment in classes for the English majors" \\ $009 F Y Y 013)$.
}

Received: July 26, 2012 Accepted: August 27, 2012 Online Published: September 4, 2012

doi:10.5539/ells.v2n4p15 URL: http://dx.doi.org/10.5539/ells.v2n4p15

\begin{abstract}
Portfolio assessment is a learner-centered assessment and it is also an assessment for learning. A study with a class of 31 first-year English education majors in 2011-2012 was conducted. The development and implementation of portfolio assessment in the integrated English course was described, and then a survey on the learner's perception toward the use of the portfolio assessment was conducted. The results showed that student have positive attitude toward the use of the portfolio assessment, the portfolio assessment developed students' language competence, enhanced their cross-cultural knowledge and promoted their learning autonomy and motivation. Finally the problems in using the portfolio were discussed.
\end{abstract}

Keywords: portfolio assessment, English education major, learning motivation, learner autonomy

\section{Introduction}

Testing is indispensable from language learning and teaching. As Bachman (1990) asserts "language tests can be valuable sources of information about the effectiveness of learning and teaching”. It should be used frequently to evaluate the effectiveness of different language teaching approaches. Nowadays, The emphasis of language teaching are shifting from the traditional way of enlightening learners solely by transmitting knowledge to what students will need to succeed in the real world. Educators take Learner's language learning ability as well as language ability into consideration and insert them into their curriculum. However, they have realized that it is rather difficult to assess these skills through traditional testing. Therefore, new forms assessment of students learning are developed to demonstrate what students are learning and what they can do with their knowledge. These new forms of assessment are known as alternative assessment, and most scholar simply use assessment instead of alternative assessment in contrast with traditional testing. Portfolio assessment is a typical instrument of the alternative assessment measures.

Different scholars adopted different definition of portfolio according to different using purpose. Broadly speaking, portfolio assessment is a purposeful collection of student work that document and assess the student's efforts, progress, and achievements in one or more areas over a period of time. The features of portfolios in the context of foreign language are summarized as: The students actively select their portfolio works; the students' self- reflection self-assessment and peer assessment are also the element a portfolio, the students participate in deciding the criteria for evaluating the portfolios, the portfolios are evaluated by persons familiar with the individual students and their learning context, the evaluation is reported qualitatively (Lynch \& Shaw 2005).

Past researches has indicated that using portfolios in foreign language education have lots of benefits: offering a multi-dimensional perspective of student progress over time, promoting self-reflection and learner autonomy and integrating learning, teaching and assessment (Delett, et al., 2001; Banfi, 2003; Yang, 2003; Allen, 2004; Nunes 2004; Bahous 2008, Lo 2010 etc). Portfolio can not only helps the learner to understand and extend learning, but make the teachers to gain insight about learning and the learner, and thus being able to adopt a more learner-centered practice. Although portfolio is an effective tool for learning and assessment, but little researches 
on the implementation of portfolio assessment with Chinese mainland EFL students has been reported. There is the largest population of English learners and test candidate in china, yet both English teaching and testing are not so satisfactory in china. So it is urgent to explore some effective ways to improve the English teaching and testing. Thus in this descriptive study I depict the process of developing the portfolio assessment in the integrated English class with Chinese English education majors to monitor the students' progress in this course and promote students' language skills as well as their autonomous learning. Then a survey was conducted to investigate the effectiveness of portfolio as a measurement instrument from the student's perspectives. Some problems associated with using portfolios were also discussed.

\section{Methodology}

\subsection{Background}

This study aimed to implement portfolio in the Integrated English course, which offered in Xuchang University in china during the academic year of 2011-2012. The Integrated English course is a required course for the first-year and second-year English majors. It is also a basic course for the students. The course goal is to help students develop their comprehensive language skills, language knowledge, language culture as well as language learner autonomy. Class meets three times for 6 hours a week. The course was offered in four terms for first-year and second-year students. The present project was for the first-year students. A pilot study was conducted in the first semester and then a formal study carried with the same class of 31 students in the second semester. Of the 31 students, males were 3 and females were 28, with ages ranging from 19 to 21 years. The pilot study and the formal study generally followed the same procedures. The main difference between the pilot study and the formal study was that students were encouraged to present some of their works by PPT in the second semester. Because most of the students have completed their computer course in semester one, it was possible for them to incorporate the computer technology into portfolio compiling. I was the instructor of the course, and also the researcher responsible for planning, conducting, and reporting the study.

Regarding the researching aim, the study posed three research questions:

1) What is the students' attitude toward the use of the portfolios in their EFL class?

2) What is students' perception of the impact of the portfolio on their learning?

3) What problems exist in implementing portfolio assessment in Chinese university context?

All students were required to complete the portfolio by the end of the semester, portfolio grade accounted for $30 \%$ of their final course grade.

\subsection{Instruments}

The data were collected by using questionnaires, weekly field notes kept by the researcher, students' portfolio and student-teacher's conference. The questionnaires consisted of six closed-ended questions and two open-ended questions. The closed-ended questions are about student's attitude toward the use of portfolio, which included 6 statements that rated on a five-point scale from strongly disagree (1) to strongly agree (5). Two open-ended questions are to gather additional information from the students on the contribution of the portfolio assessment to their learning and the problems exist in using the portfolio.

The weekly field notes recorded my observations throughout the project which included the students' response to the use of portfolio, problems or difficulties students encountered in creating a portfolio and my reflections. Students' portfolio and the conference with the students also served as a source of the data collection.

\subsection{The Process of Developing Portfolio Assessment}

The implementation of portfolio assessment has no fixed model. With referring to the models of the portfolio assessment in the foreign language classroom in previous researches (Delett etc2001, Padilla 1996, Lo 2010), the present portfolio assessment was implemented in seven steps: planning the assessment purpose, determining Portfolio tasks, establishing criteria for assessment, determining organization, preparing the students, monitoring the portfolio, and assessing the portfolio.

\subsubsection{Setting the Purpose of the Portfolio}

Discussion and negotiation concerning the purpose is the first phase when portfolios are introduced to a class (Pollari, 2000), since the purpose should guide the portfolio outline. From the very beginning, I guided the students to negotiate on the purposes of using portfolio assessment. The purpose was finally decided to assess student's progress in the integrated English course, to increase student involvement in learning, and to develop student's integrated language skills as well as autonomous learning ability. Once the purpose was decided, I 
made it clear to everyone what they were expected to do, and how, why and for what purpose.

\subsubsection{Determining Portfolio Tasks}

According to the teaching aims of the Integrated English course and the purpose of using the portfolio, the portfolio tasks included all the works that shows students' ability to use English in any of the four skill areas: listening, reading, writing, or speaking and the progress in cross-cultural awareness. the sample of the works included audio or videotapes of student's free speech, story retelling, or other kinds of dialogue or a discussion on a given topic related to the text learned; PPT of a reading report or cultural information related to the text learned; word document summary of listening material, or just an piece of written essay on a topic or a script of a oral tasks (students can present the oral task in class and put the script in the portfolio) and so on.

\subsubsection{Establishing Criteria for Assessment}

The teaching and learning syllabus for Chinese English majors (level 2) are used as the assessment goal. Regarding speaking and listening tasks, assessment encompasses pronunciation, fluency, content, and accuracy. As for some types of oral tasks such as storytelling or group discussion, Assessment also encompasses vividness and timing. As to reading and writing, Students' works were assessed by both the teacher and peers in terms of content, organization, coherence and fluency, wording, grammar, and mechanics. In final portfolio grading, completeness (various learning activities and the evidence of the revision of the works by using the students and teacher's feedback), documentation (works were dated and explained), self-reflection and assessment (depth of self-reflection toward the material and activities of this course and carefulness of the assessment of progress and learning in the course), language (whether language use is clear and correct), and design (well organized) are used as the criteria. The students and teacher discussed and agreed on the criteria for each types of task during the portfolio keeping process together.

\subsubsection{Determining Organization}

The portfolio consisted of four parts: 1) representative samples of students' work during the semester in listening, speaking, reading, writing, and culture; a written explanation (cover sheet) for each sample describing its significance to their progress in learning English; and 2) learning journals and reflections (reflections on his or her learning and on the portfolio in general); 3) all the attestations (including self-assessment, peer-assessment and teacher's feedback) 4) Weekly time management sheet and monthly and semester personal goals setting and checking, and a final summative assessment to $t$ describe his or her progress this semester, strong and weak areas, plan for improving weak areas, and a self-assessment of work during the semester; 5) all the guidelines to create portfolio, including basic requirement for the course, general idea about the portfolio assessment, criteria for the whole portfolio assessment, rubrics for the tasks, standard description of levels in teaching syllabus for English majors etc, all entries in a portfolio should be dated.

\subsubsection{Preparing the Students}

Portfolio is an interactive assessment tool; student's involvement is essential. But, in this study, none of the students had any experience of creating portfolios. So to guide the students through the process of producing the portfolio became very important. At the beginning of a semester, students are told about this project. We discussed portfolios as a learning and assessment tool in general. Then I presented the main principles of the portfolio and basic requirements in our course. Corresponding handout were also given to the students. The students showed interest in the new assessment, but many students showed great concern about their ability to manage it. I wrote down the students' reactions in my field note (I kept recording students' response during the whole process of portfolio implementation), to remove students worries, Guidelines for portfolio compilation are provided at the start of the semester. I know it takes time for the students to grasp the knowledge and skills for this new assessment, so, during the whole process, I am patient to explain the project repeatedly, helped the students to use the guidelines and do some portfolio tasks, model the students to conduct self-reflection and assessment. So the students along with the teacher involved the whole process of portfolio in establishing purpose, deciding the tasks and establishing criteria, monitoring the process and assessing the portfolio and so on.

\subsubsection{Monitoring the Portfolio Assessment}

Several management tools were developed to assist students in maintaining their portfolios. Once a week, students were required to peruse their material to include in their portfolio and wrote reflective statements for pieces they have selected. To help students improve their efficiency of planning and time management, Students were required to set goals and assess their progress weekly and monthly. each week, 15 minutes were given to the students for peer conferencing and assessment regarding process made in learning, 6-8 students had the chance 
to presented his or her portfolio task to the class, the teacher gave guidance as well as feedback. In the mid-semester, all the students turned in their portfolio for the teaching's inspection. During the semester, a 'portfolio celebration' was hold, which offers a forum for both supportive assessment and social learning in a. in a portfolio celebration, students get feedback and encouragement from their peers and, at the same time, seeing the different work produced in the group, they learn from their peers and their work. At the beginning of the semester and at the end of the semester, the students were asked to write a semester goal and a semester assessment. Students are often encouraged to keep a log to monitor and reflect on their portfolio works and the whole portfolio processes. During the whole process, I kept using class meetings to inquire the students about the problems or difficulties they encountered in compiling the portfolio, and encourage the students to keep their portfolios.

\subsubsection{Assessing the Portfolio}

The grading scheme of this portfolio system includes summative and formative assessments. Formative assessments take forms as class conferences and peer and self-assessment in this study. With the teacher's guidance, the students conducted the formative themselves frequently by referring to the rubrics and detailed criteria in class. By the end of the semester, the students' portfolios are given to me for final assessment. I browsed through all the student's portfolio, then I have a one-to-one conference with the student, each student are given 15 minutes to tell about their portfolio, and answer my questions, then suggest a grade for their portfolios and give the reasons. Considering the students' self-assessments and rationales and their works, I gave an overall grade for the whole portfolio by using holistic scoring, taking Students' language proficiency as well as their effort into consideration. In addition to the grade, I also gave a more comprehensive descriptive assessment of the portfolio, pointing out its strengths and weakness, and give suggestions for improvement. The portfolios assessment discussion becomes a dialogue where the student is an active participant, not only an object being assessed.

The portfolio was formally implemented from the beginning of the march to the end of the June in 2012, all the students turned in their portfolio on time, and most students were very active and worked hard to complete the required tasks, except one boy who only produced considerably little work in his portfolios. However, students showed greater variation in their abilities in reflecting, assessing and planning their learning. The data was collected in June.

\section{Results and Discussion}

\subsection{Students' Attitude toward Portfolio Assessment}

The first part of the questionnaire consist of six statements which are about student's attitude toward portfolio assessment , they are: (1)Portfolio as a more effective assessment compared to traditional assessment; (2) creating portfolio is a very helpful beneficial learning experience;(3) creating portfolio is very important to me; (4) I will ask my student to create portfolio in my future teaching; (5) I like to regard portfolio as a part of my learning experience; (6) I have confidence in completing the portfolio tasks. The questionnaire was administered to the students by the end of June, 2012; all the students (31) completed the questionnaires and returned it with their portfolio.

The results showed that the majority $(84 \%)$ of the students considered portfolio as a more effective assessment compared to traditional assessment (Table 1). Most (81\%) perceived portfolio as a helpful and beneficial learning experience and like to regard portfolio as a part of learning experience $(82.5 \%)$, creating portfolio is also thought important by the majority (81\%). Item 4 and 6 received comparatively the lower rating with $23.3 \%$ student reporting they are not confident in creating portfolio, while $58 \%$ students are not sure whether they will using the portfolio in their future teaching.

Table 1. Students' attitude toward portfolio assessment

\begin{tabular}{llllll}
\hline & $\begin{array}{l}\text { Strongly } \\
\text { Agree }\end{array}$ & Agree & Undecided & Disagree & $\begin{array}{l}\text { Strongly } \\
\text { disagree }\end{array}$ \\
\hline 1 & 58.1 & 25.8 & 16.1 & & \\
\hline 2 & 29 & 51.6 & 16.1 & 3.2 & 3.2 \\
\hline 3 & 12.9 & 67.7 & 16.1 & & 3.2 \\
\hline 4 & 19.4 & 22.6 & 54.8 & 3.2 & \\
\hline 5 & 29 & 53.5 & 12.9 & 3.2 & \\
\hline 6 & 16.1 & 61.3 & 23.3 & & \\
\hline
\end{tabular}


The results showed the students generally have positive attitude toward the portfolio assessment, although some students are not so confident about producing their portfolio. The result is corresponding to my observations in my field notes and conference. Students' lack of confidence and certainty in compiling portfolio and using portfolios in their teaching is not surprising, as a first-year university students, they are heavily influenced by the tradition standardized entrance examinations test, and they know little about the alternative assessment (like portfolio assessment), it takes time, effort for them not only to know it, but also to acquire some new skills it required, it is really a challenging task for some students.

\subsection{Student's Views of the Impact of Portfolio Assessment on Their Learning}

The second part of the questionnaire is about student's ideas about the impact of keeping portfolios assessment in the integrated classes on their learning. Generally speaking, the students considered keeping portfolios rewarding as well as demanding. According to the students' response, the advantages of keeping a portfolio could be categorized as: 1) promoting responsibility, 2) developing learner autonomy, 3) developing language skills and cross-cultural awareness, 4) Increasing learning motivation and confidence.

The frequently mentioned issue by the students was responsibility. The results were consistent with previous findings that keeping a portfolio increase student's learning responsibilities (Pollari, 2000; Barootchi et al, 2002). Keeping a portfolio requires responsibility, in the whole process of the portfolio assessment, the students are required to be involved in the decision-making along with the teacher, Moreover, the idea of keeping the tasks in a portfolio may increase the necessity of doing them, and the weekly plan sheet reminded them of what they should be doing throughout the week. We may say, Student's consciousness of responsibilities increased as a result of involving in the assessment and learning actively and deeply, although their willingness and abilities to take responsibility over their own learning varied.

Keeping a portfolio developed the student's autonomous learning ability. By compiling a portfolio, the students were able to frequently set goals, reflect on their learning results and check on their progress, conduct self-assessment and peer-assessment by consulting the given criteria with the teacher's guidance. These experience make students aware of their personal strengths and weaknesses (Delett et al. 2001) and get a better understanding of the learning and assessment, develop their self-reflection ability and learner autonomy (Alabdelwahab, 2002; Lo, 2010), they are more capable to plan and direct their learning. Keeping a portfolio also have changed some student's bad study habits and make them more disciplined. It also coincided with the previous research that compiling the portfolio also helped students to extend their learning approach and explore new learning materials from the Internet, instead of just limiting themselves to learning in the classroom or from textbooks (Lo, 2010).

Developing student's integrated language skills and critical thinking were also considered as major impacts of portfolio on the student's learning. Being different from the tradition testing, Portfolio assessment is task-based assessment, it assess students' language use in some specific context. By compiling a portfolio, the students get a better understanding of the learning goal and language communication ability, they realized that learning was not just for testing, learning is to develop their communicative language ability; By doing portfolio task, they have the chance to use the language in class and out of class; these practice developed their language communicative ability effectively, especially listening and speaking ability and cultural sensitivity. In this study, Student's favorite task was PPT presentation, most students liked to present the cross-cultural tasks by PPT before the class, although preparing PPT takes time. Some student's PPT is very creative and interesting. The experience of preparing or sharing the PPT works effectively helped student's learn different cultures. By doing these demanding tasks in compiling portfolios, student's critical thinking as well as problem-solving ability also developed.

The portfolio building experiences also increase student's learning motivation and confidence as the previous research indicated (Murat \& Sibel, 2010). Completing and demonstrating a portfolio task make students feel accomplishment and confident. Moreover, a portfolio demonstrated student's works, learning processes and effort as well as their ideas, interests and hobbies, so it provided me more information about student's learning and thought, then I can provided the student thorough and descriptive feedback, keeping a portfolio also provide a chance for the student to get more feedback from their classmates, all these encouraging and appropriate feedback from the teachers and students seemed to be very effective to promote student's learning motivation. Furthermore, creating a portfolio fostered collaborative learning environment. Some activities as portfolio celebration helped students learn some learning method from others and develop their own meta-cognitive skills.

\subsection{Problems in Implementing Portfolio Assessment}

One problems associated with implementing portfolio was the peer-assessment. The students reported that the 
management system (monitoring system) implemented in this study has been successful in helping students become actively involved in planning, assessing and reflecting upon their English learning, yet some problems still exist in monitoring system. One problem is related to the peer-assessment. Peer conferences and peer-assessment is an important component of the management system in our portfolio assessment implementation, since it can help students get meaningful feedback on their work and provides the social reinforcement to encourage students to be task focused. Yet some peer-assessment gives a little feedback and is not so helpful. Two main reasons can be categorized, one reason is that some students have poor language competence, the other is that some students expressed they still lack some required assessment skills. More training for the students still seems necessary for successful portfolio implementation.

Another problem associated with using portfolio was time-consuming. The problem of time-consuming in using portfolio has been commonly recognized, in this study, most students also agreed that compiling portfolio cost much time. All the data I got from my field notes and conference and student's portfolio indicated that most diligent and excellent student think it was quite rewarding and they can manage it; Yet some students claim that keeping portfolio is a burden to them, although they admitted portfolio was helpful to their learning. The reason behind this problem is complicated: one reason may be that some student's mismatching learning styles as the previous study indicated (Caner, 2010); there were some other reasons: some student worried about their future job-hunting, since they are heavily dominated by the standardized test, they wanted devoted more time to try to pass some certificate examination instead of compiling a portfolio; some students were lack of autonomous learning strategies or need more training in developing required knowledge and skills; while s a few students were just not so active toward learning. How to scaffold these students to deepen their self-reflection and realize the value of portfolio, knowing that portfolio is a creative process and needs extra attention in every phase of it may be the key to solve the problem. Meanwhile, guide the student to form a positive attitude toward learning and life is also important.

\section{Conclusions}

The portfolio assessments have strong educational significance. As a teacher, I got more feedback on my teaching and lot of information about students' learning, which is very helpful to improve my teaching. Students were involved deeply and thoughtfully in learning and assessment practices. They developed a lot both as an autonomous language learner and as a language user by compiling a portfolio. They became aware of the differences between the traditional test and the portfolio assessment; most students have the positive attitude toward the portfolio assessment although some problems still exist in the implementation. More descriptive portfolio assessment research can be carried out to explore how portfolio assessment can be used more productively in different EFL classroom context.

\section{References}

Alabdelwahab, S. Q. (2002). Portfolio assessment: A qualitative investigation of portfolio self-assessment practices in an Intermediate EFL Classroom. Saudi Arabia. Ohio State University.

Allen, L. Q. (2004). Implementing a culture portfolio project within a constructivist paradigm. Foreign Language Annals, 37(2), 232-39. http://dx.doi.org/10.1111/j.1944-9720.2004.tb02196.x

Bachman, L. (1990). Fundamental considerations in language testing. Oxford: Oxford University Press.

Bahous, R. (2008). The self-assessed portfolio: A case study. Assessment \& Evaluation in Higher Education, 33(4), 381-393. http://dx.doi.org/10.1080/02602930701562866

Banfi, C. S. (2003). Portfolios: integrating advanced language, academic, and professional skills. ELT Journal, 57(1), 34-42. http://dx.doi.org/10.1093/elt/57.1.34

Barootchi, N., \& Keshavarz, M. H. (2002). Assessment of achievement through portfolios and teacher-made tests. Educational Research, 44(3), 279-288.

Caner. A. (2010). Students views on using portfolio assessment an EFL writing courses. Anadolu University Journal of Social Sciences, 10(1), 223-236.

Delett, J. S., Barnhardt, S., \& J. A. ( 2001). Kevorkian. A framework for portfolio assessment in the foreign language classroom. Foreign Language Annals, 34(6), 559-68.

Lo, Y. (2010). Implementing reflective portfolios for promoting autonomous learning among EFL college students in Taiwan. Language Teaching Research, 14(1), 77-95.

Lynch, B., \& P. Shaw. (2005). Portfolios, power, and ethics. TESOL Quarterly, 39(2), 263-297. http://dx.doi.org/10.2307/3588311 
Murat, H., \& H. Sibel. (2010). The European Language Portfolio in ESP classes: A case study of learner reflection and self-assessment. European Journal of Social Science, 12(4), 671-684.

Nunes, A. (2004). Portfolios in the EFL classroom: disclosing an informed practice. ELT Journal, 58(4), 327-35. http://dx.doi.org/10.1093/elt/58.4.327

Padilla, A. M., J. Aninao, \& H. Sung. (1996). Development and implementation of student portfolios in Foreign language programs. Foreign Language Annals, 29(3), 429-38.

Pollari, P. (2000). This is my portfolio: Portfolios in upper secondary school English studies. Retrieved on April 28, 2010, from http://eric.ed.gov/PDFS/ED450415.pdf

Yang, N. (2003). Integrating portfolios into learning strategy-based instruction for EFLcollege students. International. Review of Applied Linguistics in Language Teaching, 41(4), 293-317. http://dx.doi.org/10.1515/iral.2003.014

\section{Author}

Huang Jizhen is an associate professor in the School of Foreign Languages of Xuchang University in China, an academic visitor in Lancaster University (2010.05-2012.05). Her main research interests include L2 reading and language assessment. E-mail: hjizhen@126.com; hjizhen@google.com 